\title{
Russian and Negative Prefixing: A Cognitive-Semantic Approach to the Negative Adjective Prefixing in Russian, Spanish, Persian, and English
}

\author{
Rajdeep Singh ${ }^{1}$ \\ ${ }^{1}$ Department of Linguistics, Payame Noor University, Tehran, Iran \\ Correspondence: Rajdeep Singh Department of Linguistics, Payame Noor University, Tehran, Iran. Tel: \\ 98-91-2858-6635. E-mail: rajdeepsm@gmail.com
}

Received: August 12, 2018

Accepted: September 21, 2018

Online Published: December 12, 2018

doi:10.5430/elr.v7n4p15

URL: https://doi.org/10.5430/elr.v7n4p15

\begin{abstract}
Negative prefixing has always been an important and intriguing morphological process, through which adjectives are formed in many different languages. However, there are limits to negative prefixing. In this study, we introduce the novel concept of Polarity Flexibility, through which the limitations for the negative prefixing are accounted for. Furthermore, we conducted an experiment to investigate whether the PF is an active cognitive process. The results of the experiment confirm our hypothesis and the fact that Polarity Flexibility does indeed influence the cognitive processing. In our study, we introduce the notion of the syntactic arrangement which influences the negative prefixing. Therefore, we compare Russian, Persian, Spanish and English in negative prefixing to show how much the cognitive processes are influenced by the syntactic formations. Russian as a representative of Slavic languages brings an important insight into the way syntax plays role in the semantic-cognitive context.
\end{abstract}

Keywords: comparative study, negative adjective prefixing, Russian, Persian, Spanish, English, polarity flexibility, polarity flexibility ratio, cognitive processing, psycholinguistics, syntax, syntactic arrangement

\section{Introduction to the Semantics of Negative Adjective Prefixing}

Adjectives have an important function, which helps to clarify emotions, senses, and feelings in a different context. From this, we have some adjectives which traditionally are associated with positive and optimistic feelings, and overall they have a positive semantic load. On the other hand, there are adjectives which bring about negative impressions, bad feelings, overall having a negative semantic load. Through the prefixing, there is the possibility to convert positive semantic direction to the negative direction. In this study, we put emphasis on the cognitive load that the negative prefixing brings about for students. In fact, the syntax and cognitive processing are so intimately inter-related that we should take both in our consideration in order to investigate the negative prefixing and the contributing cognitive load. Languages, indeed, show different negative prefixing schemes, and it is important to find out the root cause of such diversities. There is a lack of proper investigation of the semantics of negative prefixing in a rather general way.

Tolskaya (2015) Investigates the Russian verbal prefixes and their conceptual and syntactic structure, suggesting that the same prefix with a consistent conceptual meaning receives part of the denotation from the syntactic structure. Peeters and czapinski (1990) investigate the notion of negativity and positivity in language, the asymmetry involved, which is called the negativity effect. They investigate how the negative information varies compared to its positive counterpart. Singh (2018) investigates the notion of similarity between important cultural words across languages and introduces the novel concept of water code and mirroring effect to point out to the cognitive process which begins within the language by the similarity of the reflection of forms. Efanova, Lutoshkina, Dronova and Natsagdorj (2015) lead a cognitive approach toward Russian prefixes, which express a relationship to the norm. In our study, we have a similar cognitive approach in regard to the semantics of the negative prefixing in Russian. Sherman (1973) conducts an experiment to verify the effects of the negative prefix on sentence comprehension and clarifies the fact that the presence of a negative prefix does indeed make the comprehension more difficult. In our study, we also conducted an experiment which converges on the comprehension difficulty caused by the presence of a negative prefix. Kennedy and McNally (1999) underscore the fact that gradability is a feature common among verbs, nouns, and adjectives, conducting an investigation which treats the deverbal adjectives. This is important as it shows that the syntax has some contribution to the adjective morphological semantics, though, in our study, we go beyond this simple notion, and show how the syntax determines the existence of the negative prefixing for adjectives. Yang 
(2015) carries on an investigation to clarify why some adjectives with the schwa in English cannot be used in a pronominal position and shows that indirect negative evidence cannot be accountable for their absence in the child early language acquisition level. This shows that there is a boundary between semantics and syntax which can affect the very use of semantics through the formation of adjectives in the language. Funk (1986) investigates the reason behind the fact that some adjectives cannot be prefixed with "in/ un", the most common negative prefix in English and German, respectively. In our study, we provide a rich answer to this question through the model of Polarity Flexibility. Blust (2003) investigates the adjective circum-fixing in Austronesian morphology and points out to the fact that syntax has an influence in the morphology. Singh (2018) introduces the novel concept of basket verb and shows how the cognitive processing influences the syntax. However, in this study, the negative prefixing is proved to be a syntactic process influencing the cognitive processing. De Clercq and Wyngaerd (2016) show the syntactic constraints for the double negation and bring evidence for such a constraint. However, in our study, we bring the main reason behind the whole notion of negativity effect when it comes to the adjective formation. Martín Arista (2010) looks through the adjective morphology in old English and points out to the fact that "un" is the most common adjective prefix, which is used exclusively with positive adjectives. Singh (2018) investigates the Norwegian and Persian spatial prepositions from the type-logical points of view to discuss their cognitive role. The cognitive processing is one of the most important features of language development and our study also contributes to the understanding of cognitive processing and comprehension, through the negative prefixing. Singh (2018) investigates the semantic and functional load of the words in the sacred context which shows how words are processed cognitively. Tribushinina and Dubinkina (2012) investigate the adjective production by Russian-speaking children with specific language impairment and find out that degree morphology is more impaired in them compared to antonyms. Based on our study, the Russian syntax can be a good reason behind this difference. In our study, through the concept of PF (Polarity Flexibility), we describe how the syntax affects the morphology of adjectives in how Russian is different compared to English. Singh (2018) investigates the concept of language change, by analyzing the different morphological processes that changed through the passage of time. Here, however, we use a similar concept, the morphological processing, to show that syntactic processes also affect the way languages evolve. Givon (1970) claims that English adjectives are not semantic primitive, but semantically based upon the verbs or nouns. In our study, we look upon the semantics for adjectives, but the fact that syntax derives the negative prefixing points out to the notion of syntax, rather than just nouns or verbs. Baldi, Broderick, and Palermo (1985) conduct some psycholinguistic experiments in order to find out the reason behind the productivity of certain negative prefixes present in English, where negative prefixing is considered to be an important feature of morphology which has deep roots in the cognitive processing. Singh (2018) works on the differences between Hausa and Persian and defines the notion of language difficulty through the differences in the syntax. Here, we also work on the syntactic arrangement which influences directly the cognitive processing.

As mentioned above, there is a lack of the proper investigation and analysis of the negative prefixing. What we try to achieve is to classify the negative prefixing inside the universals of language. Furthermore, we put emphasis on the semantics of negative prefixing and the way languages allow the negative prefixing. This is important since we later show how the negative prefixing forms a cognitive load. This cognitive load can slow down the process of language acquisition and comprehension.

\section{Negative Adjective Prefixing}

Negative adjective prefixing helps expand the lexicon fast and is an important feature in adjective formation. The fact is that we find in many languages a morphological process to convert a positive adjective to a negative one. However, the other way around, that is the conversion of a negative adjective to the positive pole is a rare case and does not happen in many languages. For example, in English, we have so many adjectives which are formed through the addition of the negative prefix "un" to the positive adjective base. However, we cannot add the same negative prefix to the already negative adjective. This is illustrated in Figure 1.

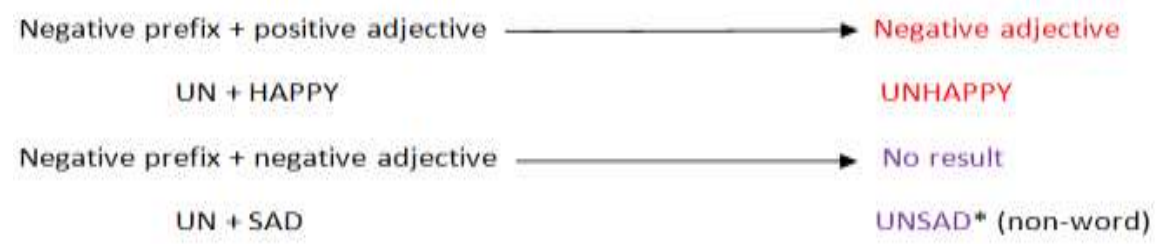

Figure 1. Negative prefix combined with a positive adjective 
This is intriguing as we expect that morphological prefixing works both ways, but in English and many other languages there seems to be a cognitive pressure, beyond the morpho-syntactic one, which forces us to form negativity from positivity. Therefore, we consider the positive adjective as the unmarked one, closer to the base, and the negative adjective as the marked one. It seems to be a universal concept since it happens in all languages, though with a different range. Figure 2 and Figure 3 show the same concept in Persian and Spanish. In Figure 2, the positive adjective "RAHAT" (at ease) is converted to a negative adjective by the prefixing NA (not), which means "not at ease and sad". In figure 3, the same prefixing process is applied to the positive adjective FORTUNADO (lucky) and the resultant adjective afortunado is a word which means sad. However, negative prefixing (a) to an already negative adjective produces a non-word.

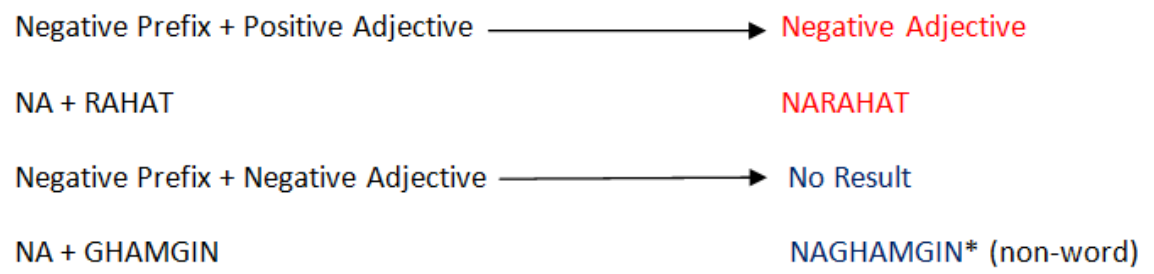

Figure 2. Negative prefix (NA) combined with positive and negative adjectives

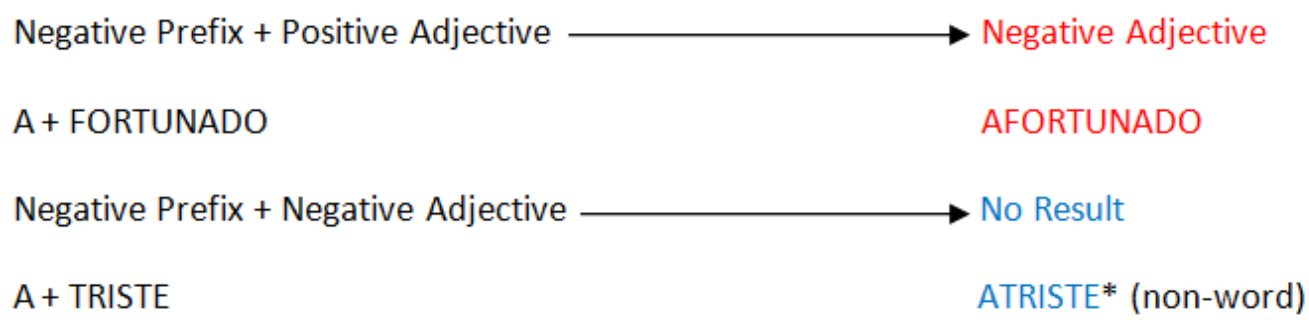

Figure 3. Negative prefix (A) combined with positive and negative adjectives

Therefore, there is a tendency to consider the positive adjective as the based form. However, in Russian, the range of this cognitive rule is different and even the reverse is possible. Consider Figure 4 and how a negative prefixing can be done with both positive and negative adjectives. Here, the negative prefix HE(not) is added to the positive adjective XOPOШO (good) and produces the negative adjective HEXOPOШO which means bad. However, here the reverse works pretty well. We can add a negative prefix HЕ (not) to an already negative adjective ПЛОХИЕ and produce a correct adjective, НЕПЛОХИЕ, which means well. Therefore, it is necessary to account for this discrepancy. Furthermore, in Russian, one can easily form negative adjectives almost without any limit. As we saw, in English, we have the adjective sad but rarely a systematic adjective unwell. This is in clear contrast to Russian, where the result of morphological prefixing is the norm and HEXOРОШО (nekhorosho) is the usual word for bad. Therefore, we have a much bigger range of possibilities in Russian, compared to English, to form adjectives and use them as a base in the language.

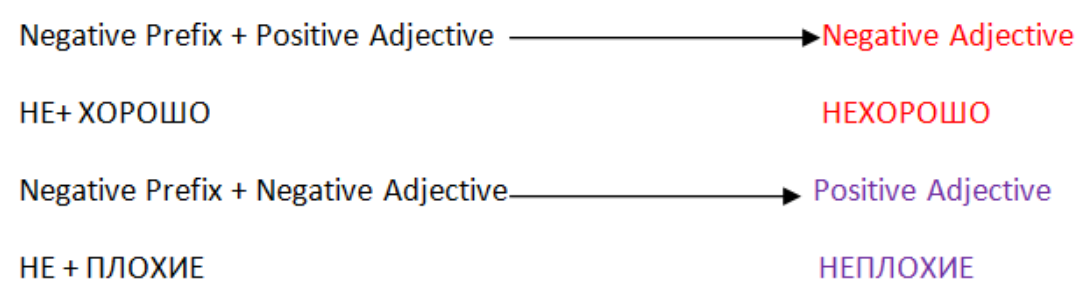

Figure 4. Negative prefix (NA) combined with positive and negative adjectives 


\section{Polarity Flexibility Universal: Syntactic-Driven Process}

As it was mentioned earlier, we have a language such as Russian where there is a less clear boundary between positive and negative adjectives as they both can be used as the base to form prefixed adjectives. Though we saw that there is a universal tendency to form negative semantics from the positive ones, it seems that Russian offers a counter-argument and makes it hard to claim that the negative should come from the positive in a systematic way. In order to solve this dilemma, we introduce the novel concept of polarity modeling and flexibility which is based on the syntax. Here, the syntax actually influences the morphology and it is an important concept, not encountered in other areas of morphology.

Polarity Flexibility Universal states that based on the simple sentence formation, the negative prefixing can be allowed or disallowed. In fact, the structure which the adjectives and negative particles form influences the possibility of negative prefixing. Therefore, the syntax determines whether the prefixing will be a word or just a non-word.

Let's consider how PFU (Polarity Flexibility Universal) works. In Russian, the verb "to be" is not used in the simple sentences in the present tense. Therefore, based on the syntax, the negative prefix can be accompanied the positive and negative adjective, providing a cognitive context for the Russian speakers to form a whole range of adjectives through the prefixing which is a morphological process. Example 1 shows this syntactic property of Russian language which does not exist in English.

Example1.

a) Я счастлив.

Ya shatsliv.

I happy (I am happy).

b) Я не счастлив.

Ya ne chastliv.

I not happy (I am not happy).

As it is shown in Example 1, the fact that there is no necessary verb to interfere in making a negative sentence and only a negative particle не (not) is sufficient, which brings the interesting cognitive process for Russian speakers to use negative prefixing with both positive and negative adjectives. Therefore, the PU is dependent on the syntax. We can contrast this Russian syntactic rule with the Persian one where the verb to be (boodan) should be present, and consequently, this makes the double polarity in Persian impossible. Example 2 shows how the verb to be is necessary in the Persian context.

Example2.

a) Man khoshhal hastam.

$$
\text { I happy am (I am happy). }
$$

b) Man khoshhal nistam.

I happy not am (I am not happy).

Therefore, the polarity is highly dependent on the syntax and it shows a cognitive processing which forms the PFR (Polarity Flexibility Ratio). In fact, through PFR we can determine the approximate range of adjectives which can be formed through negative prefixing, producing both positive and negative adjectives. Slavic languages, such as Russian, allow the negative prefixes not only on evaluative adjectives but also dimensional ones. This much richer range of negative prefixing is shown in Example3.

Example3.

невысокий стол

nevisokii stol

not high table (a low table)

Therefore, Russian as many other Slavic languages is a language with the high PFR (Polarity Flexibility Ratio) due to its syntax and the special arrangement of adjectives and other parts of speech elements. Here, the syntax affects the cognitive process which is a unique situation since we usually see the cognitive processes form the syntactic 
elements. We can show the PF (Polarity Flexibility) and the PFR (Polarity Flexibility Ratio) as it follows in Figure5 and PFR formula.

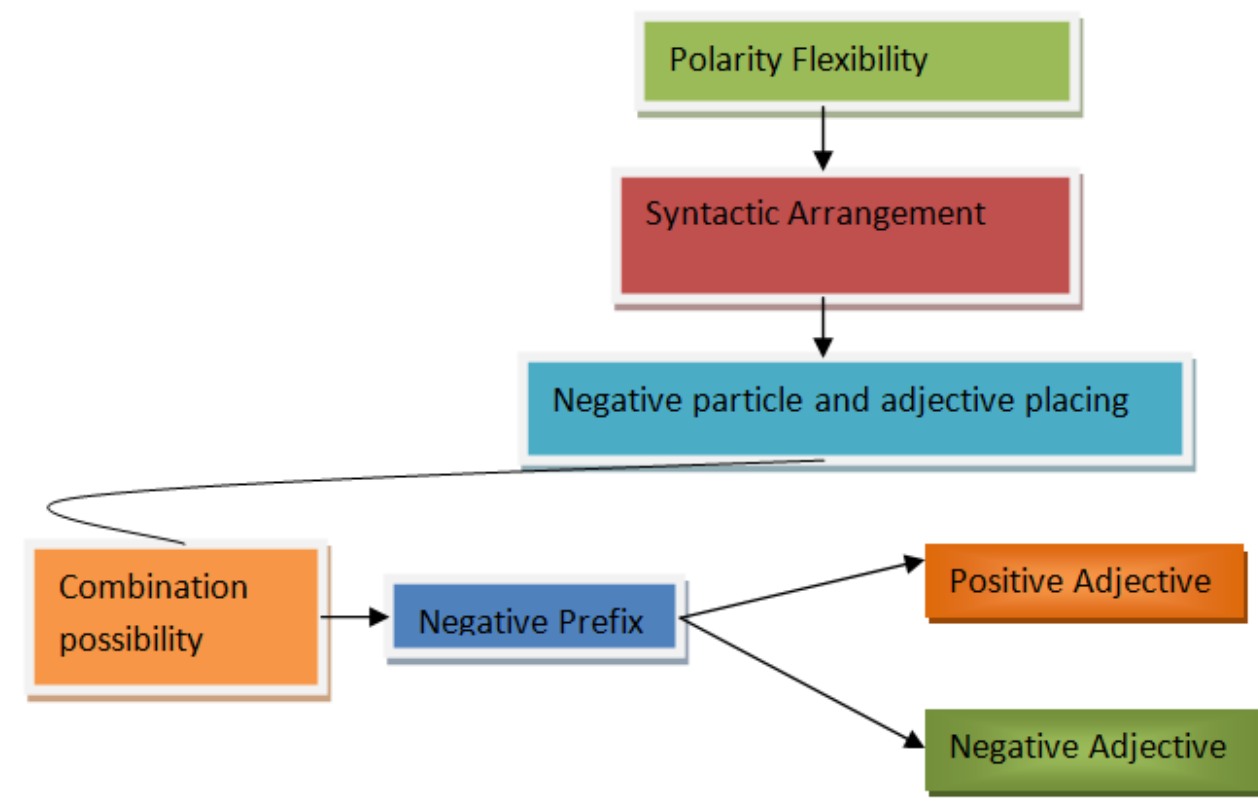

Figure 5. Polarity Flexibility

PFR formula:

$$
\text { PFR }=\frac{\text { actual adjectives }}{\text { possible adjectives }}
$$

PFR states the ratio of formed adjective compounds compared to the possible adjective compounds which is an important notion in order to classify languages based on the negative prefixing possibilities.

\section{Testing Polarity Flexibility}

PF (Polarity Flexibility) is a cognitive process which has important pedagogical implications as well. We tested a group of Persian learners of Russian to see how much the PF affects their learning. Our group consists of 20 students, with equal female/male ratio. We surveyed our students after the first semester, and then the coding process began. Based on our coding schemes, the most problematic area (45 percent) in elementary level was the PF processing since students were used to forming negative adjectives through prefixing and they had formed a cognitive process in their mother tongue (Persian) which does not have a high PF. This indicates that in the second language teaching, we should pay more attention to the PF and how it can affect students' future performance. Some of the comments by students regarding the comprehension difficulty in the survey are as follows:

Female Student (A1): Russian sounds beautiful to me and I really like to learn it. However, whenever I see words, rather adjectives, which have negative prefixing, I get confused as I expect a negative meaning, while often they have a positive meaning.

Male student (A4): I love learning Russian and the verb conjugation is not hard for me. However, whenever I get to the lexical items and especially adjectives which have ne (not), I should read twice to make the meaning and when I hear a text, I get lost in the comprehension.

Note. A1 and A4 are the numbers we used to specify students in our survey and coding. 
As it can be seen in A1 comment, the confusion that negative prefixed adjectives cause for her makes the whole comprehension rather tricky. This is what we observed by the listening audio lessons where whenever there was a negative prefixed adjective, students tend to think of the meaning as positive, which is how the cognitive processing in Persian words. However, in Russian, there are many instances where the negative prefixing brings a positive meaning, just as in neplokhii (literally not bad).

\section{Conclusion and Results}

Negative prefixing is an important tool to expand lexicon in languages. However, as we saw earlier, many languages put limitations on the usage of negative prefixing. By introducing the notion of PF, we brought an explanation as to why negative prefixing is so limited in many languages and has many preconditions to be present before being able to apply it. In fact, PF is a syntactic process which influences the cognitive process in order to expand the different concepts. Converting positivity to negativity is one of the fundamental features of negative prefixing. However, as we saw, in reality, the negative prefixing is subject to Polarity Flexibility. In reality, PF puts a limit to the cognitive processing for the adjective formation and defines the boundaries of negative prefixing. It is an important discovery which can influence the future research projects in the psycholinguistic field. Through the experiment we conducted in this study, we found out that the already formed PFR in any language makes it harder to expand the ratio for a new language. Just as we stated earlier, for a Persian speaker with a limited PFR, learning Russian will be harder as Russian has a high PFR. Thus, teachers should pay attention to the different PFR in languages in order to help students with the comprehension. Another important point is the usage of Polarity Flexibility Ratio in analyzing languages that can be problematic for students when it comes to the cognitive processing load because of their high flexibility ratio. In these circumstances, great care should be taken to avoid the over-complication and confusion. One of the best solutions is to raise students' awareness of the negative prefixing and the role it plays in the development of language competence. When students are aware of the negative prefixing differences between their mother tongue and the foreign language, they can develop different strategies to deal with this, consequently gaining self-confidence in their language acquisition route.

\section{References}

Baldi P., Broderick V., Palermo D. S. (1985). Prefixal Negation of English Adjectives: Psycholinguistics Dimensions of Productivity in Historical Semantics, Historical Word-Formation, J. FISIAK J. (éd.), Berlin, New York, Amsterdam : Mouton de Gruyter, 1985, 33-57. https://doi.org/10.1515/9783110850178.33

Blust, R., A. (2003). Three notes on early Austronesian morphology. Oceanic Linguistics, 42(2), 438-478. https://doi.org/10.1353/ol.2003.0018

De Clercq, K. \& Wyngaerd, G., V. (2016). A Constraint on Double Negation. Manuscript. Universiteit Gent. Retrieved from: https://www.angl.hu-berlin.de/department/staff-faculty/professors/alexiadou/abstracts/de-clerq-and-vanden-wyn gaerd.pdf

Efanova, L.G., Lutoshkina, O.S., Dronova, L.P. \& Natsagdorj, S. (2015). On Cognitive Approach to Language when Studying Russian Prefixes Expressing Relation to the Norm. Procedia -Social and Behavioral Sciences, 215, 67-71. https://doi.org/10.1016/j.sbspro.2015.11.575

Funk, W.,P. (1986). Towards a definition of semantic constraints on negative prefixation in English and German, in Kastovsky, D. and A. Szedek (eds.), Linguistics across 102 historical and geographical boundaries. Volume 2: Descriptive, contrastive and applied linguistics. Berlin: Mouton de Gruyter, 877-889. https://doi.org/10.1515/9783110856132.877

Givon, T. (1970). 'Notes on the semantic structure of English adjectives', Language 46, 816-37. https://doi.org/10.2307/412258

Kennedy, C., \& McNally, L. (1999). From event structure to scale structure: Degree modification in deverbal adjectives. In T. Matthews, \& D. Strolovitch (Eds.), Semantics and linguistic theory 9 (pp. 163-180). Ithaca, NY. https://doi.org/10.3765/salt.v9i0.2820

Martín Arista, J. (2010). Lexical negation in Old English. NOWELE-North-Western European Language Evolution, 60/61, 89-108. https://doi.org/10.1075/nowele.60-61.05ari

Peeters, G., \& Czapinski, J. (1990). Positive-negative asymmetry in evaluations: The distinction between affective and informational negativity effects. In W. Stroebe \& M. Hewstone (Eds.), European review of social psychology (Vol. 1, pp. 33-60). New York: Wiley. https://doi.org/10.1080/14792779108401856 
Singh, R. (2018). Derivational Grammar Model and Basket Verb: A Novel Approach to the Inflectional Phrase in the Generative Grammar and Cognitive Processing. English Linguistics Research, 7(2). https://doi.org/10.5430/elr.v7n2p9

Singh, R. (2018). Norwegian and Persian spatial prepositions: a novel comparative and syntactic approach to the spatial prepositions. KAAV international journal of English, literature, and linguistics, 5, 1-8. Retrieved from: http://www.kaavpublications.org/journals/journal-5/abstract/abstract-1788.pdf

Singh, R. (2018). A Cognitive Approach to the Semantics in the Sacred Context: Semantic and Symbolic Function of Sacred Words. English Linguistics Research, 7(3). https://doi.org/10.5430/elr.v7n3p1

Singh, R. (2018). Language change and directionality: A novel model for language change in Persian and Iranian languages from the sociolinguistic perspective. KAAV International journal of English, Literature, and linguistics, 5, 1-8. Retrieved from: www.kaavpublications.org/journals/journal-5/article/article-1876.pdf

Singh, R. (2018). Error Analysis of Persian Learners of Hausa Language: Cognitive Approach to Errors. Journal of Literature, Languages and Linguistics, 45, 10-15. Retrieved from: https://iiste.org/Journals/index.php/JLLL/article/viewFile/42853/44147

Singh, R. (2018). Mirroring Effects and the Water Code: A Cognitive-Semantic Approach to Natural Morphology in the Religious-Cultural Context. Journal of Literature, Languages and Linguistics, 46, 37-41. Retrieved from: https://iiste.org/Journals/index.php/JLLL/article/download/43453/44769

Sherman, M. A. (1973). Bound to be easier? The negative prefix and sentence comprehension. Journal of Verbal Learning and Verbal Behavior, 12, 76-84. https://doi.org/10.1016/s0022-5371(73)80062-3

Tolskaya, I. ( 2015). Verbal prefixes in Russian: Conceptual structure versus syntax. Journal of Linguistics 2015, 51(1), 213-243. https://doi.org/10.1017/s0022226714000206

Tribushinina, E., \& Dubinkina, E. (2012). Adjective production by Russian-speaking children with specific language impairment. Clinical Linguistics \& Phonetics, 26, 554-571. https://doi.org/10.3109/02699206.2012.666779

Yang, C. (2015). Negative knowledge from positive evidence. Language, 91, 938-953. https://doi.org/10.1353/lan.2015.0054 